\title{
Psychological support
}

Psychological support for the 1996 British Olympic team was twofold: support provided by team psychologists who worked exclusively with personnel from one sport, and support provided by psychologists assigned to British Olympic headquarters (HQ) who were available to help any member of the team. This paper discusses both roles while focusing primarily on the $\mathrm{HQ}$ positions filled by the authors.

\section{Pre-departure phase}

Before departure, team psychologists prepared athletes and coaches for the emotional melting pot of Olympic competition, helping them plan for situations they might encounter. Typically, this work involved the refinement of pre-competition routines, the enhancement of competition skills such as relaxation, concentration, and visualisation, and helping to develop effective teamwork. Most Olympic competitors experience anxiety symptoms. The potential for underperformance is therefore significant. Strategies such as simulation training and "what if?" scenarios also tended to be used by team psychologists to help athletes develop effective responses to difficult situations.

\section{Holding camp phase}

Most sports completed their preparations at the British Olympic holding camp located in Tallahassee, Florida, which used the outstanding training facilities of Florida State University. The Tallahassee camp was well organised with excellent logistical support and provided a productive working environment for all concerned. The take up for psychological services in Tallahassee, where two HQ psychologists remained throughout the four week camp, divided approximately into $25 \%$ for athletes, $25 \%$ for coaches and team managers and, perhaps surprisingly, $50 \%$ for other support staff.

Psychological services were provided by a daily drop-in service, continuing mental training where links already existed, provision of mental training tools such as relaxation tapes, some psychometric monitoring using mood profiles, 24 hour standby support (fortunately not called upon), and what could be termed "social monitoring"spending leisure time with athletes and coaches to gauge their general wellbeing.

An example of the support provided is that given to a first time Olympian who, when contemplating the forthcoming competition, could foresee only disaster. His anxiety was reduced by reorienting his competition goals away from potential negative outcomes (fouling out, finishing last) and towards controlling the competitive process (positive mental rehearsal, an effective routine, etc). A further example involved an athlete with a phobia for snakes, which are common in Florida, and who, therefore, needed considerable therapy, including a psychologist accompanying her on training runs. Other issues included interpersonal difficulties and organisational stress generated by lack of role clarity or role acceptance.

For all concerned, the holding camp acted as a refuge from the impending maelstrom of Atlanta itself. It did not, and was not intended to, simulate the environment of the Olympic village. Ironically though, the relaxed atmosphere of Tallahassee might have contrasted too sharply with Atlanta, generating a false sense of wellbeing and a slight loss of focus among those attending.

\section{Olympic village phase}

One HQ psychologist was resident in the Olympic village. He offered a drop-in service in addition to promulgating his availability through notice boards and pigeon holes. These produced few contacts. The most constructive route for contacts was through referral to the sport psychologist by $\mathrm{HQ}$ medical and physiotherapy staff, illustrating the value of a cohesive team of staff from across all support disciplines.

Group cohesion issues were prominent in the Games environment, accounting for about $60 \%$ of the support provided. Of the remainder, most issues involved stress, concentration, or injury. For example, one group of competitors identified communication and stress management as key issues. Working with the HQ psychologist, they developed greater understanding of how their separate stress responses exacerbated the communication problem. Key phrases were established which enabled them to flag their differing needs, while during practice sessions they worked hard at enhancing the quality of the support they provided for one another.

Another case involved one of the archery competitors, who had trouble "getting the shot away" due to excessive tension in his fingers. The solution devised was a combination of progressive muscular relaxation and attentional control, whereby thoughts were directed away from the site of the tension towards another cue - in this case the pressure of the draw string against his cheek-which acted as a trigger for the release of the arrow.

\section{Comparison of team psychologist and HQ psychologist roles}

The two roles were very different. Team psychologists, because they had known the individuals concerned for a longer time, could take a relatively proactive stance towards possible interventions with athletes. The HQ role tended to focus less on performance issues and more on organisational factors. Moreover, it was entirely reactive to demand from others. Periods of inactivity seemed to cause feelings of guilt and superfluity on the part of the psychologists. From discussions across support disciplines it was found that such feelings are not uncommon in the Olympic environment, which by its very nature has a tendency to intensify emotional responses.

\section{Recommendations for future Games}

Psychologists in Tallahassee and Atlanta were unanimous in advocating the appointment of support personnel much earlier, possibly 18 months to two years in advance. This would allow for more detailed involvement with athletes, coaches, and managers before departure. The best protection of psychological wellbeing or enhancement of performance was achieved with those individuals with whom a good working relationship and mutual trust already existed. Coaches and athletes were, quite rightly, reluctant to change well tried routines at the Olympic site, even if ultimately they proved unproductive. It is apparent that those psychologists with experience across a broad range of sports are better placed to function effectively at Olympic HQ, and hence this should be an important criterion when psychologists are appointed.

PETER TERRY

LEW HARDY

GRAHAM JONES SHELAGH RODGERS 